\title{
Public emergency department: the psychosocial impact on the physical domain of quality of life of nursing professionals
}

\author{
Moisés Kogien ${ }^{1}$ \\ José Juliano Cedaro²
}

Objectives: to determine the psychosocial factors of work related to harm caused in the physical domain of the quality of life of nursing professionals working in a public emergency department. Method: cross-sectional, descriptive study addressing 189 nursing professionals. The Job Stress Scale and the short version of an instrument from the World Health Organization to assess quality of life were used to collect data. Robert Karasek's Demand-Control Model was the reference for the analysis of the psychosocial configuration. The risk for damage was computed with a confidence interval of $95 \%$. Results: In regard to the psychosocial environment, the largest proportion of workers reported low psychological demands (66.1\%) and low social support (52.4\%), while $60.9 \%$ of the professionals experienced work situations with a greater potential for harm: high demand job (22.8\%) and passive work (38.1\%). Conclusions: low intellectual discernment, low social support and experiencing a high demand job or a passive job were the main risk factors for damage in the physical domain of quality of life.

Descriptors: Quality of Life; Psychosocial Impact; Nursing; Emergency Medical Services.

\footnotetext{
${ }^{1}$ MSc, RN, Hospital Estadual de Pronto Socorro João Paulo II, Secretaria Estadual de Saúde de Rondônia, Porto Velho, RO, Brazil.
} ${ }^{2}$ PhD, Adjunct Professor, Departamento de Psicologia, Universidade Federal de Rondônia, Porto Velho, RO, Brazil. 


\section{Introduction}

From the important contributions of Christopher Dejours to the psychodynamics of work, a new strand of studies on occupational health has highlighted that the relationship between work and the health-disease continuum is not neutral, reinforcing the conception that every productive activity has the potential to promote either health or disease, depending on the way the elements of work organization and process are configured and how these interconnect with the worker's subjective characteristics ${ }^{(1)}$.

In general, a particular sort of work's psychosocial environment encompasses an interaction of a series of determinants of a psycho-sociological nature (psychosocial factors) that are closely related to that work's specific characteristics, such as work process, organization, structure, and the dynamics of interpersonal relationships ${ }^{(2-3)}$.

The environment and the psychosocial factors that compose it have a dichotomous interaction with the worker's health and, in this paradoxical relationship, psychosocial factors can be distinguished through their repercussions on the professional's life, based on two main references: those of psychosocial aspects, which, depending on the circumstances in which they occur, are beneficial and have a salutary effect protecting the worker's health, or aspects that play a significant role in the manifestation of diseases(3).

There are numerous and diverse deleterious psychosocial aspects in a work environment. These interact among themselves and have repercussions on the institution's psychosocial climate and particularly on the workers' quality of life and physical and mental health ${ }^{(4)}$. The work process and the way work is organized in the urgent care and emergency departments of the Brazilian public health system are strongly marked by these paradoxical psychosocial relationships ${ }^{(5)}$ with the potential to harm the health of workers.

We note that these psychosocial elements arising in the work environment have the potential to compromise any of the spheres of an individual's health and quality of life. This study addresses the potential harm that can be caused to the physical dimension of human health because it directly contributes to increased absenteeism at work, sick leave or the need to readapt to functions, reduced productivity, and a potential loss in the quality of service delivery.

Mainly based on the finding of work's pathogenic role that the psychosocial environment can play and considering the daily routine of a public emergency department, we question in this study how the psychosocial organization of the work of nursing professionals is configured in this environment and what psychosocial elements are characterized as statistically significant risk factors with the potential to harm the physical domain of these professionals' quality of life.

Because the psychosocial environment is composed of multiple and varied elements that encompass the psychological and social dimensions of work, we adopted the three basic dimensions assessed by the DemandControl Model (DCM) proposed by Robert Karasek, which are decision latitude concerning the work process, psychological demands and social support ${ }^{(6-7)}$, as the theoretical-methodological reference in order to analyze the psychosocial configuration.

Therefore, this study's objective was to determine the main factors that can harm the physical domain of the quality of life of nursing professionals working in a public emergency department. The reason behind the study is that, among health workers, nursing professionals are the ones who spend more time directly assisting patients and, as some studies report, these professionals are particularly subject to the risk of physical stress and illness accruing from the way work is organized in the hospital environment ${ }^{(8-9)}$.

\section{Method}

This descriptive and cross-sectional study was conducted with the nursing professionals of a public state emergency department located in Rondonia, Brazil. The study was approved by the Institutional Review Board at the Federal University of Rondonia (CEP/UNIR) in December 2010 (CAAE: 6563.0.000.047-10) and complied with all the procedures necessary to ensure the participants' confidentially and privacy.

The sample was composed of 189 nursing professionals: 36 nurses and 153 nursing technicians, with a level of significance of $5 \%$, a sample error of $4.7 \%$ and an estimated proportion of $50 \%$. The sample was nonprobabilistic and intentional based on the professionals' availability and agreement to participate in the study. All the professionals working in the studied facility who provided care during the period of data collection were considered potential participants and those who freely consented signed free and informed consent forms.

Data were collected through self-applied instruments, which were independently completed by the interviewees, though the participants were free to 
ask for the researchers' help. A set of three instruments was applied to the participants: one socio-demographic questionnaire developed by the authors that also addressed job-related questions; the WHOQOL-brief (10), which is proposed by the World Health Organization to assess quality of life; and a brief version of the Job Content Questionnaire translated into Portuguese that assesses psychosocial aspects of the work environment (Job Stress Scale)(6-7,11).

\section{Statistical analysis of the data}

After the individual analysis of each instrument using descriptive statistics, which is recommended by the authors, we verified which psychosocial elements were statistically associated with the variables related to the quality of life assessment. For that, Person's Chisquare test (or Fisher's exact test, when necessary) was used for the categorical variables and Student's $t$ test was used for the continuous variables. Then, multivariate analysis using logistic regression was performed and the odds ratios (OR) were obtained. All the psychosocial and job-related variables that had previously presented associations with a level of significance of $\leq 0.05$ were included in the logistic regression.

Only seven questions from the WHOQOL-BREF that assess the physical domain of quality of life were considered in the analysis of this domain, in addition to the general indicator obtained through the arithmetic average of the sum of the scores assigned to each of the seven questions; a number between one and five can be attributed to each question. The average result of this domain was then multiplied by four in order to enable a comparison between the values used in the WHOQOL-100 instrument, and finally were converted into a numerical scale that ranges from 0 and 100 , in which "zero" represents the lowest level of quality of life and "100" (maximum) represents the highest level of quality of life ${ }^{(12)}$.

After the domain's general score was computed, this variable was dichotomized using as a reference the median of the obtained results. The professionals who scored equal or below the cut-off point were considered to have low quality of life in the physical domain and those who scored above the median were considered as having a high level of quality of life. These steps were repeated for each of the questions in this domain. Note that questions 3 and 4 had their scores inverted in order to standardize the direction of grading in all the instrument's questions. The gradual increase in the answer was equivalent, in the same proportion, to an increase in the positive result of that facet ${ }^{(10)}$.

The Job Stress Scale (JSS) is composed of 17 questions and includes the three basic dimensions proposed by the DCM: psychological demand; control over work; and social support. Of all the questions, five assess the levels of psychological demand addressing the job's quantitative aspects, such as time, demand for and speed in which tasks are performed, in addition to conflicts among the different work demands. Six questions assess the degree of control the worker has over her/his job and another six questions assess social support by addressing one's relationships with peers and superiors. We note that the dimension "control" can be divided into two subscales that assess the worker's intellectual discernment (composed of four questions) and decision-making power (composed of two questions) $)^{(11,13)}$.

The computation of the scores of each of the psychosocial dimensions was accomplished by the totaling the scores attributed by the professionals to the respective question in the JSS in which a value, between 1 (less frequent) and 4 (more frequent), is attributed to each answer provided by the participants. Some of the instrument's questions also present an inverse score, hence the values were inverted before summing up the items so that the strength of all the responses would have the same direction ${ }^{(11,13)}$.

The theoretical model adopted for the psychosocial assessment predicts that the interaction between different levels of demand (high or low) with different levels of control (high or low) result in different occupational experiences, according to the degree of exposure to occupational stressors ${ }^{(11,13)}$. To identify the groups experiencing different levels of intensity or psychosocial aspects at work, we used the medians of the dimensions as the cut-off points ${ }^{(11,13)}$.

The software used to construct the database in this study was the Microsoft Office Excel for Windows ${ }^{\circledR}$ version 2010 and the Statistical Package for the Social Sciences (SPSS) version 20 was used for the statistical computation.

\section{Results}

In regard to the main socio-demographic and jobrelated variables (Table 1 ), the sample was characterized as having a prevalence of females (76.2\%), an average age of 32.79 years old $(\mathrm{SD}= \pm 8.06)$ and was mainly composed of nursing technicians $(81 \%)$. 
Of all the nursing professionals working in the studied emergency department, $53.4 \%$ have a partner, $44.5 \%$ have worked in the facility for more than five years, and $60.73 \%$ have a weekly workload equal to or less than 40 hours.

Table 1 - Social-demographic and work characterization of the study's sample ( $N=189), 2012$, Porto Velho, RO, Brazil

\begin{tabular}{|c|c|c|}
\hline Variables & $\mathbf{n}$ & $\%$ \\
\hline \multicolumn{3}{|l|}{ Profession } \\
\hline Nurse & 36 & 19.00 \\
\hline Nursing technician & 153 & 81.00 \\
\hline \multicolumn{3}{|l|}{ Gender } \\
\hline Male & 45 & 23.80 \\
\hline Female & 144 & 76.20 \\
\hline \multicolumn{3}{|l|}{ Weekly workload } \\
\hline$\leq 40$ weekly hours* & 116 & 61.70 \\
\hline$>40$ weekly hours & 72 & 38.30 \\
\hline \multicolumn{3}{|l|}{ Time in the facility } \\
\hline$\leq 1$ year & 35 & 18.50 \\
\hline $1-5$ years & 70 & 37.00 \\
\hline$>5$ years & 84 & 44.50 \\
\hline \multicolumn{3}{|l|}{ Level of quality of life } \\
\hline High QoL physical domain & 91 & 48.10 \\
\hline Low QoL physical domain & 98 & 51.90 \\
\hline \multicolumn{3}{|l|}{ Level of Social Support } \\
\hline High Social Support & 90 & 47.60 \\
\hline Low Social Support & 99 & 52.40 \\
\hline \multicolumn{3}{|l|}{ Level of Psychological Demands } \\
\hline High Psychological Demand & 64 & 33.90 \\
\hline Low Psychological Demand & 125 & 66.10 \\
\hline \multicolumn{3}{|l|}{$\begin{array}{l}\text { Interactive Categories of the } \\
\text { Demand-Control Model }\end{array}$} \\
\hline Active work & 21 & 11.10 \\
\hline
\end{tabular}

Table 1 - (continuation)

\begin{tabular}{lccc}
\hline & Variables & n & $\%$ \\
\hline Passive work & 72 & 38.10 \\
High demand & 43 & 22.80 \\
Low demand & 53 & 28.00 \\
\hline
\end{tabular}

* One participant did not answer

In regard to the aspects related to the physical domain of these professionals' quality of life, the sample was characterized by a prevalence of low scores for quality of life (51.9\%) (Table 1 ).

As for the situation of work assessed by the Job Stress Scale, we verified that $60.9 \%$ of the sample falls into one of two profiles, which according to the DCM have the highest potential to compromise quality of life: high demand work (22.8\%) and passive work $(38.1 \%)$. Based on the interactive categories, we determined that the largest proportion of the sample of nursing professionals perceive themselves as having low psychological demands (66.1\%) (Table 1 ).

Additionally, it was possible to determine, based on the analysis of the work site's psychological environment, that social support, intellectual discernment, and the DCM job profiles behaved as statistically significant risk factors with the potential to harm the quality of life of nursing professionals. Among the social and job-related variables, only the "number of jobs" was characterized as a risk factor to compromise the workers' satisfaction with their sleep and rest (Table 2).

We note, that even though the facets of pain/ discomfort, dependency on medication, and ability to work, integrate the assessment of the physical domain of quality of life, they were not included in Table 2 because they did not present statistically significant associations with any of the psychosocial or job-related variables studied in this sample of professionals.

Table 2 - Psychosocial and social-job-related factors associated with low scores/harmed physical domain of quality of life and the respective facets, 2012, Porto Velho, RO, Brazil

\begin{tabular}{lccc}
\hline & Adjusted OR * & CI 95\% & \\
\hline Physical domain of quality of life - general score & 1 & & $<0.01$ \\
High social support & 2.81 & $1.43-5.53$ & $<0.01$ \\
Low social support & 1 & $1.34-6.41$ & 0.04 \\
High intellectual discernment & 2.94 & & \\
Low intellectual discernment & 1 & $2.06-5.58$ & \\
Low demand work & & & 0.01 \\
High demand work & 1 & $1.21-5.68$ & (continue...)
\end{tabular}


Table 2 - (continuation)

\begin{tabular}{|c|c|c|c|}
\hline & Adjusted OR * & CI $95 \%$ & $p$ \\
\hline Low demand work & 1 & & \\
\hline High demand work & 3.34 & $1.28-8.72$ & 0.01 \\
\hline Passive work & 2.15 & $0.99-4.65$ & 0.05 \\
\hline \multicolumn{4}{|l|}{ Facet mobility } \\
\hline High social support & 1 & \multirow{2}{*}{$1.12-4.67$} & \multirow{2}{*}{0.02} \\
\hline Low social support & 2.29 & & \\
\hline High intellectual discernment & 1 & \multirow{2}{*}{$1.77-8.56$} & \multirow{2}{*}{$<0.01$} \\
\hline Low intellectual discernment & 3.89 & & \\
\hline \multicolumn{4}{|l|}{ Facet sleep and rest } \\
\hline High social support & 1 & \multirow{2}{*}{$1.46-5.94$} & \multirow{2}{*}{$<0.01$} \\
\hline Low social support & 2.95 & & \\
\hline Only one job & 1 & \multirow{2}{*}{$1.62-6.96$} & \multirow{2}{*}{$<0.01$} \\
\hline Two or more jobs & 3.36 & & \\
\hline Low demand work & 1 & \multirow{2}{*}{$0.91-6.30$} & \multirow{2}{*}{0.05} \\
\hline High demand work & 2.40 & & \\
\hline \multicolumn{4}{|l|}{ Facet daily life activities } \\
\hline High intellectual discernment & 1 & \multirow{3}{*}{$1.22-5.67$} & \multirow{3}{*}{0.01} \\
\hline Low intellectual discernment & 2.63 & & \\
\hline Low demand work & 1 & & \\
\hline High demand work & 2.63 & $1.07-6.46$ & 0.03 \\
\hline Passive work & 2.64 & $1.21-5.77$ & 0.01 \\
\hline
\end{tabular}

* OR adjusted for socio-demographic variables

\section{Discussion}

In general, the organization of work in Brazilian public emergency departments is complex and permeated by deleterious, ambiguous, and paradoxical work situations, especially in terms of the worker's physical and psychological health. Numerous factors contribute to the negative and unsound configuration of this work environment. The causes include social, political-organizational issues and the very essence of this type of service ${ }^{(14)}$.

Public urgent care and emergency services should be characterized by their capacity to maintain human life and as having efficient diagnostic and therapeutic methods to reduce mortality, morbidity and sequelae. These facilities tend, however, to be recognized by other characteristics that tarnish their reputation, such as: overcrowding, poor service conditions, scarcity of resources, work overload and the fast pace of the work required of the professionals providing care. Currently, some of these characteristics are linked to the popular image of a public emergency department ${ }^{(4-5,14)}$.

Coupled with these there is a negative psychological load inherent to critical units in which there is always the possibility of a fatality. Hence, pain, distress, helplessness, anxiety, fear, hopelessness, feelings of abandonment and loss permeate emergency units and are psychological demands with a potential deleterious effect on the health and quality of life of workers ${ }^{(4-5)}$. Therefore, the way the work is organized in emergency departments together with the configuration of the psychosocial environment where the work occurs have an important and significant association with the genesis of occupational stress ${ }^{(5,14)}$.

Stress is a distinct, complex psychological situation that directly impacts the physical, psychological and social spheres of human life. This phenomenon, according to the way and intensity with which it is manifested, interferes to a lesser or greater degree with some facets that compose the concept of quality of life ${ }^{(6)}$.

Multiple theoretical perspectives attempt to understand the manifestation of occupational stress and its impact on human life. One of these perspectives originated in Robert Karasek's DCM. This model, widely used in recent studies, has been a useful instrument to assess psychosocial environments and to understand the relationship they have with the genesis of occupational stress and its repercussions in the lives of workers ${ }^{(6-7)}$. It enables an isolated assessment of the interactions among levels of psychological demands, control over the work process, and social support that are experienced by workers in their occupational spaces ${ }^{(6-7)}$.

In relation to the analysis of interactions among the DCM variables, the main ones and those that are the 
best known are the combinations among the levels of psychological demands and control. These interactions generate four job experiences that characterize welldelineated, specific and distinct experiences in work environments ${ }^{(6-7,15)}$, with extremes marked by the possibility of worker illness (high demand job) or by an impact on the motivation of workers to develop and apply behavioral standards in their occupational environment (active job). The intermediate situations can lead to reduced productive capacity with a decline in one's global activity or can lead to motivational inertia in relation to the work (passive job) (6-7,15-16).

According to the DCM, a "high demand" job is considered the profile with the greatest potential of illness because it is characterized by the presence of high demands combined with low levels of control over the occupational activity(15-16). When workers experience an overload of work and have little control over how to resolve it, over time they experience a high level of physiological excitement and increased tension occurs in the nervous and cardiovascular systems. If these conditions persist for a very long time and the individual is not able to reduce his or her work demands, his/her organism enters a process of wear and tear and the loss of internal homeostasis ${ }^{(6-7,15-16)}$.

The second profile with the greatest potential to harm the quality of life of workers is referred to as a "passive job". In this framework workers may experience a gradual reduction in their ability to resolve general problems that emerge in their work environment. They experience high levels of boredom and dissatisfaction related to the repetition of tasks and the reduced ability to face intellectual challenges(15-16). Even though workers fitting the profile "active job" experience high demands, they present higher levels of satisfaction with work and lower levels of stress because they can control their activities and perceive the demands as opportunities to improve their competence, selfefficacy, personal growth and as opportunities to develop or improve their abilities ${ }^{(15-16)}$.

In regard to a "low demand" job, the DCM considers it as being the one with the lowest potential to harm workers' health; but even though it has high levels of control, it does not offer the sort of potential for the worker to develop new skills or enable personal growth as the profile "active job" does(6-7,15-16).

This study's findings are in agreement with the assumptions of Robert Karasek's theory. Both profiles with potential to harm workers' health were those that presented statistically significant risks of generating occupational stress in the physical dimension of the quality of life and its correlated facets.

The nursing professionals that fit the profile of "high demand" jobs have a significant likelihood of obtaining low general scores in the physical domain of quality of life $(O R=2.34 ; p=0.04)$, of showing a perception of tiredness and fatigue in everyday life $(O R=3.34$, $p=0.01)$, of being dissatisfied with sleep $(\mathrm{OR}=2.40$, $p=0.05$ ), and dissatisfied with their ability to perform daily activities (OR=2.63, $p=0.03)$ when compared to those with a "low demand" profile (Table 2).

We also verified that perceiving oneself as being in a low demand occupation and as experiencing low control over the work process (passive job) was a statistically significant factor for tiredness and fatigue $(O R=2.15, p=0.05)$ and dissatisfaction with one's ability to perform routine tasks $(O R=2.64$, $p=0.01$ ) (Table 2).

While these two job experiences diverge in relation to the perceptions of workers in terms of levels of psychological demands, the main similarity between them is the low level of control one has over the work process. This fact leads us to reflect upon the way with which each of these psychosocial elements interacts with the workers' health and quality of life.

Demands refer to pressure of a psychological nature to which workers are subject in their work environment and may originate in the intensity of labor to be performed in a given time or a mismatch between the workers' ability and the activity at hand ${ }^{(15)}$. The literature shows that even though demands are commonly characterized as negatively affecting the health of workers, not every demanding situation is harmful. In the work environment, for instance, when demands exceed the worker's abilities and knowledge, there is an opportunity to mobilize adaptive forces and energy $^{(15)}$. In relation to control, diverse studies defend the view that work conditions that favor the development of this element on the part of workers and enable the use and improvement of one's abilities are important for the job to function as a healthy component in the lives of people, leading to wellness, pleasure and health(6-7).

When one's level of control over work is low, the levels of stress accumulated over a long period of time reduce one's ability to learn and assimilate new coping strategies(6), consequently leading workers to physical and emotional burnout, helplessness and absenteeism. Hence, appropriate control over work is an important way to protect workers from the unsound effects of contemporary jobs and is an important way to achieve 
wellbeing, physical health and quality of life in the work environment ${ }^{(6-7)}$.

In the DCM, the dimension control is assessed based on the integration of two distinct subcomponents: intellectual discernment and decision-making power. Epistemologically, we can understand the essence of intellectual discernment based on the Marxist dialectic between labor and its transforming potential. When an individual changes nature during the work process $\mathrm{s} /$ he concomitantly modifies him/herself as his/her latent potentialities are encouraged or developed. These are situations that enable the worker to develop his/ her skills, whether improving old skills or acquiring new ones, which compose the core of the dimension "intellectual discernment"(6-7,15-16).

From this perspective, we can understand intellectual discernment as a variable with transforming potential. This is the case in the sense that, as the more frequent the opportunities to learn and to assimilate new practices, skills and knowledge, the more frequent are the opportunities to change behavior and habits. New learning can promote healthy habits and minimize behaviors/practices that pose a risk to health, preparing the worker's ability to satisfactorily face stressors in the work environment and, consequently, improve his/her perception of quality of life.

Social support, in turn, as a psychological characteristic of labor in the context of the DCM, includes components of a collective nature that are able to change the dimensions of an individual order of the relationship between demand-control and health. Social support refers to global levels of useful and cooperative social interaction existing in the work environment, encompassing the relationships among peers and hierarchical superiors in the organization ${ }^{(6-7,17)}$.

Social support is considered an important variable in the maintenance of health. Perceiving oneself as having low levels of social support may be associated with deleterious manifestation and negative effects on health. Various studies addressing different professions report that not perceiving oneself to be supported in the work environment makes the worker more vulnerable to cardiovascular disorders, stress, and physical and emotional burnout ${ }^{(6-7,17-18)}$.

There are few studies in Brazil assessing the relationship between low social support and harmful effects on the physical aspects/quality of life of nursing workers. Studies usually employing the DCM focus only on the role played by psychological demands and control over work and their respective interactions. Nonetheless, some European studies conducted in the last decade with samples of different professions have shown important associations between lack or low level of social support at work with harmful effects on workers' health. Much of this evidence is in agreement with the relationships found in this sample of nursing professionals.

In addition to evidence concerning the deterioration of the general state of health and quality of life, low levels of social support have been associated with the presence of sleep disorders, gastrointestinal problems, increased risk of heart disease, the emergence and complications of musculoskeletal pain, excessive fatigue and tiredness, reduced functional capacity and increased absenteeism $^{(17-18)}$.

The mechanisms through which social support in the work environment affects health, wellness and quality of life are diverse. It may act as a mechanism that attenuates the deleterious effects of psychosocial stressors at work or it may enhance the development of new skills or behavior, or encourage the acquisition/ improvement of coping strategies. On the other hand, in the lack of social support, negative effects on workers' health are often observed(6,17-18).

\section{Final considerations}

The work performed in an emergency department can be considered a negative element determining levels of quality of life of professionals working in this environment because these facilities tend to have an often-frustrating pace of urgent and emergency demands that are potential sources of distress and emotional burnout. Work overload, overcrowding, poor conditions, insufficient and inappropriate human/ material resources, and the quality of interpersonal relationships are factors that may contribute to low quality of life.

We note that the presence of high psychological demands, which is characteristic of the work performed in an emergency department, plays a relativized role in the genesis of occupational stress and worsened quality of life and can be harmful when associated with a lack of control over the work process and a low perception of social support. High levels of social support can be directly associated with improved levels of physical health, since they enable the individual to better adapt to the deleterious effects of stressful events, reducing the negative consequences on the organism, promoting wellness, a predisposition to health and improved indicators of quality of life. 


\section{References}

1. Dejours C. Psicodinâmica do Trabalho: contribuições da escola Dejouriana à análise da relação prazer, sofrimento e trabalho. São Paulo: Atlas; 2010. 145 p.

2. Villalobos F, Gloria H. Vigilancia epidemiológica de los factores psicosociales: aproximación conceptual y valorativa. Cienc Trab. 2004;6(14):197-201.

3. Cassel EJ. The contribution on the social environment to host resistence. Am J Epidemiol. 1976;104:107-23.

4. Urbaneto JS, Silva PC, Hoffmeister E, Negri BS, Costa BEP, Figueiredo CEP. Workplace stress in nursing workers from an emergency hospital: Job Stress Scale analysis. Rev. Latino-Am. Enfermagem. 2011;19(5):1122-31.

5. Dal Pai D, Lautert L. Work under urgency and emergency and its relation with the health of nursing professionals. Rev. Latino-Am. Enfermagem. 2008;16(3):439-44.

6. Karasek RA, Theorell T. Healthy work: stress, productivity, and the reconstruction of working life. Nova Iorque: Basic Books; 1990. 381 p.

7. Karasek RA. Job demand, job decision latitude, and mental strain: implications for job redesign. Adm. Sci.

Q. 1979; 24: 285-308.

8. Kirchhof ALC, Magnago TSBS, Camponogara S, Griep RH, Tavares JP, Prestes FC, et al. Condições de trabalho e características sociodemográficas relacionadas à presença de distúrbios psíquicos menores em trabalhadores de enfermagem. Texto Contexto-Enferm. 2009;18(2):215-23.

9. Magnago TSBS, Lisboa MTL, Griep RH, Kirchhof ALC, Guido LA. Aspectos psicossociais do trabalho e distúrbio musculoesquelético em trabalhadores de enfermagem. Rev. Latino-Am. Enfermagem. 2010; 18(3); 991-1003.

10. World Health Organization. WHOQOL-BREF: Introduction, administration, scoring and generic version of the assessment. Programme on Mental Health. Geneva; 1996.

11. Alves MGM, Chor D, Faerstein E, Lopes CS, Werneckd GL. Versão resumida da "Job Stress Scale" adaptação para o português. Rev Saúde Pública. 2004;38(2):164-71.

12. Pedroso B, Pilatti LA, Frasson AC, Scandelari L, Santos CB. Qualidade de vida: uma ferramenta para o cálculo dos escores e estatística descritiva do WHOQOL-100. $28^{\circ}$ Encontro Nacional de Engenharia de Produção; 13 a 16 de outubro de 2008; Rio de Janeiro, Brasil. Rio de Janeiro: Associação Brasileira de Engenharia de Produção; 2008. 13. Alves MGM, Chor D, Faerstein E, Werneckd GL, Lopes CS, Estresse no trabalho e hipertensão arterial em mulheres no Estudo Pró-Saúde. Rev Saúde Pública. 2009;43(5):893-6.
14. Awada SB, Rezende WW. Serviços de emergência: problema de saúde pública. In: Martins HS, Damasceno MCT, Awada SB. Pronto-Socorro: condutas do Hospital das Clínicas da Faculdade de Medicina da Universidade de São Paulo. Barueri: Manole; 2007.

15. Araújo TM, Graça CC, Araújo E. Estresse ocupacional e saúde: contribuições do Modelo Demanda-Controle. Cienc Saúde Coletiva. 2003;8(4):991-1003.

16. Araújo TM, Aquino E, Menezes G, Santos CO, Aguiar L. Aspectos psicossociais do trabalho e distúrbios psíquicos entre trabalhadores de enfermagem Rev Saúde Pública. 2003;37(4):424-33.

17. Giovanetti RM. Saúde e apoio social no trabalho: estudo de caso de professores da educação básica pública [dissertação de mestrado]. São Paulo (SP): Faculdade de Saúde Pública da Universidade de São Paulo; 2006. 141 p.

18. Costa SV, Ceolim MF, Neri AL. Sleep problems and social support: Frailty in a Brazilian Elderly Multicenter Study. Rev. Latino-Am. Enfermagem. 2011;19(4):920-7. 